\title{
Business, Industry and Higher Education Collaboration: A Panacea in Developing Professional Work-Ready Graduates
}

\author{
Ahmed Umar Rufai ${ }^{1}$ \\ Ab Rahim Bin Bakar2 \\ Abdullah Mat Rashid ${ }^{3}$ \\ 1-3Faculty of Educational Studies, University Putra Malaysia, 43400 UPM Serdang, Malaysia \\ Corresponding author: Ahmed Umar Rufai; Email: el_rufaifarouk@yahoo.com
}

\section{Doi:10.5901/mjss.2015.v6n6p512}

\begin{abstract}
The purpose of this paper is to explore how institutions of higher learning, industries and businesses work together to accomplish mutual goals, intended to help shape and inform up-to-date curriculum and course design. The aim was to improve mutual understanding and exchange of ideas between the Education and business sectors that can lead to produce professional work-ready graduates. The research method was essentially qualitative case-study design method (Yin, 2003), was used. The researcher collected documents, conducted semi-structured interviews and recorded observations at the selected multinational companies and recognized institutions of higher learning. The emergent themes from the data, in form of field notes, interview scripts, audio recordings and information from documents, representing the views of both Educationists and Industrialists were analyzed. The four emergent themes as characterized by the participants views on collaborative efforts between business and Education were identified as; cooperative study programme, technical support and programme delivery, representation in the institution governing council and collaboration through shared facilities. The study represent a means of contributing quality in teaching and learning graduate employability skills, that is vital in the survival and challenge to industry to succeed in an increasingly competitive world market. This paper attempts to provide new ways of thinking as well as formal flexible commitments from business and Education in forming partnership, that enable both sectors share the needs, problems, issues, strengths and weakness of in training professional work-ready graduates.
\end{abstract}

Keywords: Business, Industry, Higher Education, Employability, collaboration.

\section{Introduction}

The interaction between institutions of higher learning and Employers in Industries and related business organizations represent a means of contributing quality education training programmes. The challenge to business and industry to succeed in an increasingly competitive world market is contingent upon skilled personnel, who learn, grow and adapt to the changing markets and technologies. Clearly, industrialization has survival stake in quality education programmes, in this regard the concept of education and business collaboration is changing and gaining momentum as a means for improving education for employability programmes. Employability Skills Framework stage 1 (2012), in its final report, argued that if the teaching and learning of Employability skills is to be valued and effective, then those who are most likely to use it (i.e. education, training and employability services sectors) need to be involved throughout the design, implementation and review stages of the training programmes. The report further stressed that unless the training programme has the support and input of potential user groups; it runs the risk of being "yet" another theoretical framework.

It has been accepted world-wide, that employer/education partnerships require new ways of thinking as well as considerable formal flexible commitment from both sectors forming partnerships with the private and public sector forces higher education school system to share the needs, problems, issues, strengths and weaknesses of educational programming, partnership also requires teachers and administrators to share the internal workings of higher education with representation from industry, business and a range of other related bodies and or stakeholders. Successful partnership can generate mutual respect and trust among education institutions and employers and allow mutual problems to be solved and shared goals reached. These outcomes may help educational leaders increase access to and improve the quality and efficiency of education for employability programmes. Opengart \& Short (2002), observed that there has also been a modification in labour market policy orientation from the security and structural workforce 
interventions to a position of employability security', where individual workers must constantly adapt to rapidly changing work environments and requirements, including emerging technologies (Butterwick \& Benjamin, 2006) these policy shifts have affected the higher institutions education sector in fundamental ways Government (particularly in the UK, Australia and Canada) have made public funding for higher institutions partially contingent upon demonstrable graduate outcomes, with emphasis on the production of 'work-ready' graduates who are competent within their disciplinary fields and possess the abilities necessary to negotiate a world of work. Muller, (1991) also observes that there is no doubt that employers are major customers of the education and training service industries, commerce and professional have argued strongly for strengthening the links between education and businesses.

The experience of Britain (UK) is pertinent in this regards since in the 1960's. Industrial organizations in Britain such as chemical companies maintained educational services for higher institutions. The industries and businesses provided a wide range of literature and other resources materials which are frequently prepared with the assistance and advice of the institutions. This effort revealed that the materials were of limited in use a teaching situation, leading to recognition of closer collaboration between institutions and industry.

At the conference on "modern chemistry in industries" in March 1968, the need for closer collaboration between institutions and industry was recommended, and it was agreed to adopt the "link scheme", a concept devised to involve industry in institutions programmes. The basic aim was to improve mutual understanding and the exchange of ideas between institutions and industry, and the objectives were among others to;

i. Help younger people obtain a clear picture of industrial life with opportunities and challenges.

ii. Enable employers and industrialist become more aware of the pattern and philosophy of educational programmes in the institutions.

iii. Provide institutions (on request) with career advice.

iv. Assistance with projects and the development of courses on industrial topics.

Nevertheless, it must also be recognized that, the public sector remains a major corporate employer across the UK and it is necessary that educational providers satisfy the needs of both private and public sector organizations. Against this background, the role of employers in the education and training process has taken on major importance following the education reform act (1988). This act has encouraged employers to become more involved by taking greater responsibility in both the school system and in post-16 educations; hence employers constitute the majority on the governing bodies of institutions of further and higher education. The experiences of the United States of America are also pertinent with regards to industry - education collaboration. Sherman, (1983) recalled that, the concept of education and industry and business entering a partnership is not new. He observed that industries of the United States have been cooperating with schools to educate youths and admits for more than a century and that the value of industries input into the educational arena is reaching new heights. According to Sherman, this collaboration is viewed as one method of providing innovations and quality for schools of the future.

Roth (1987) reported the four ways in which partnership may benefit schools and industries as presented by Madelein Hammings (1984) of the National Alliance of Business by;

i. Providing other individuals and the institutions, opportunities to perceive another organizations point of view and a chance to win anallay.

ii. Expanding the capabilities of participating institutions to deal with the challenges that each entity must meet in its line of operations and helping to build the kind of understanding that creates support.

iii. Serving as a means of contributing to quality education programme.

iv. Bringing increased access to and knowledge, access time human resources and financial assistance from other sectors in the community as well as reducing the cost and liability of doing business for each participant.

Roth, (1987), noted that historically, personnel in Education have maintained close relations with the industries. According to him, the scope of such relation must be expanded and developed if industry involvement is to be valuable and meaningful rather than merely voluntary or advisory Education. Roth observed that Advocates are needed who may help higher Education keep instruction and equipment up to date. In his article it was reported that the Congress of the United States recognized the critical importance of industry /Education partnerships and emphasized this concept in the

Carl D. Perkins Vocational Education Act of 1984, which was amended through 1994 and 1998, one of the nine statements of purpose of the act (19984), the original beginning was to promote greater cooperation between public agencies and the public sector in preparing individual for employment.

In promoting the quality of vocational education in the United States, and in making the system more responsive to the labour market in the States. Emphatic in PL 98- 524 was the emphasis that Congress placed on Education/industry partnership. For example, in a paper presented at the PL 98 -524 Implementation Conference sponsored by the American Vocational Association, Johnson (1985) extracted more than 50 excerpts from the act that pertained to 
collaboration among public and private sectors in the economic development of the United States.

Hungerford (1984) reported that in 1984 the Illinois State Board of Education issued a policy and plan for Education for employment, the result of nearly two years of study. Findings of the study indicated that a number of systematic problems caused education for employment programmes to be less than adequate in dealing with the broad issues of technical, social and economic changes. Five problem statements were focused upon in a summary of the study. One problem specifically addressed was the relationship between the schools and industry. The conclusion was relationship between the schools providing education for employment and the business, labour and industrial sector been largely restricted to activities involving advisory councils and voluntarism rather than those exemplifying shared responsibility for educating workers of the primary education and training thrusts of present. Today has been the emergence of new partnerships and collaborative efforts between industry and education. These collaborative efforts can work to the benefit of both education and industry programme, this is due to the fact that, as the rate of technological change accelerates, both industry and education are faced with increasing demands for technical related instruction.

\subsection{Key Ingredient to Successful Partnership between Industry and Education}

In a report titled, computerized manufacturing, automation, employment, education and the assessment (1984) made the following recommendations for education, training and re-training. A key ingredient is successful programmable automation instructional programmes was identified as; close cooperation between industry, education, labour and government in such areas as skills assessment, curriculum design, equipment acquisition, location of qualified instructors and job placement.

Moser (1986) reported that two key factors which influence establishing linkages between Business/Industry and higher institutions include among other things;

i. The way educational institutions carries out its philosophy, and

ii. The related working of the internal college process.

He emphasized that, if the educational institutions philosophy includes a firm commitment of serving the business sector, certain process must remain flexible, some of those include the institutions willingness to;

i. Revise, which may include updating current curricula

ii. Customize the institution to a company's specific needs. This may include conducting needs assessment, in addition to developing new materials which could be present in a variety of formats, such as short courses or workshops.

iii. Offer instruction on site and provide training using the company's equipment.

iv. Whenever possible, institutions policies should allow provision for awarding credit or certification for job skill training which may be applied towards a degree or certificate programme and instruction, which should be shared or jointly conducted by company representatives.

However, a major consideration for the success of the programme is for the company representatives and the institutions for each organization. In many companies there should be a contact person bearing a title such as training manager or personnel director who is responsible for co-coordinating all educational activities, it is vital for the key contact person of the institution to ascertain who in the company is responsible for training functions. The institution should also have one representative who serves as a liaison between the company and the institution.

There are many different types of collaborative ventures between Industry/Business and Education, Greenberg (1984) identified the following six patterns of collaboration notably among them includes; cross training, cooperative work study, traditional, Adult Continuing education, shared facilities and the consultant pattern.

Many of these patterns overlap. According to Greenberg, the oldest and the most common collaborative efforts between Business/Industry and education are co-operative work study programmes that make it possible for students to receive part of their education on the job where they can gain skills that are best learned with all the problems and constraints that are part of the private sector operation. Another common example of such collaborative efforts is the cross training pattern, this is a method that utilizes a combination of industry and education personnel, facilities and curriculum. Cross training efforts permits both education and industry to pool their resources. Higher institutions are well suited for the consultant pattern of collaboration, they are able to operate to a pro-active role, serving industry as technical expert and consultant related education, training and retraining while strengthening and enriching their teaching research programmes within the area of consultation. 


\subsection{Purpose/Objective of the Study}

The purpose of this paper is to explore how institutions of higher learning, business and industries work together to accomplish mutual goals, that are intended to help shape and inform up-to-date curriculum and course design. The aim was to improve mutual understanding and exchange of ideas between the higher Education and business/industry sectors of the economy that can lead to produce professional work-ready-graduates. Specifically, the paper objectives of this paper include among others;

i. Enable employers and industrialists become more aware of the pattern and philosophy of educational programmes in higher institutions

ii. Provide higher institutions on (request) with career advice.

iii. Help young graduate obtain a clear picture of Business/Industrial life with opportunities and challenges.

iv. Assistance with projects and the development of courses on industrial topics.

There is no doubt however, that greater collaboration between education and business sector will not only satisfy the immediate needs of graduate of higher institutions, but also ensure that employers themselves are satisfied by the quality of the product.

\section{Methodology}

This study being qualitative, multiple case study design was used to investigate how institutions of higher learning and Business/Industry collaborate in the training of professional work-ready graduates and make comparison and or generalizations.

The investigation has three main primary sources of data collection, observation, interviewing and documents. The researcher decided to use multiple data sources rather than only one source in order to capture the contextual complexity of the topic under investigation, and in many instances the researcher spent an extended period of time onsite to interact regularly with the participants besides, the researcher also records details about the context in which the whole case was found including information about the physical environment and other historical factor that have bearing on the situation. The study has twenty-one (21) participants, three (3) representatives, one (1) each from three large multinational companies and eighteen (18) academic staff, and one (1) each representing one department or a particular field of study.

The criteria for identification and selection of the participants, purposeful sampling was used to select respondents, who were thought to be excellent examples of individuals with relevant experiences, that could contribute in providing rich information on the topic under investigation (Merriam, 2014).

The approach to this qualitative inquiry being case study, the analysis was carried in three stages; familiarization and organization of data; coding and reducing of data; interpretation and representation of data. In the first step, interview summaries were written immediately after the interview (Yin, 2003) while audio recordings were verbatim transcribed and analyzed in sequence. The data generated was first analyzed by 'open coding, where the researcher finds as many categories as possible. In particular, this requires reducing and organizing the data, while searching for patterns and discovering what it important. The researcher therefore examines and interprets the data collected in form of field notes, interviews transcripts audio recordings and information from documents. Cresswell, (2007) describes the data analysis spiral that once that data are collected they must be organized and managed.

\section{Results}

While seeking answers to the research objectives, the participants representing industries and institutions of higher learning were asked to provide information on the kind of institution and employer relationship that exists in terms of support for training programmes. The key questions asked include among others; do the Business/Industries participate in any capacity course plan design and implementation of Educational programmes? If yes, what is the extent of such involvement? What are the kinds of collaboration that exists between such institutions (tertiary) and industries? How does such collaboration impact changes on graduate employability skills? What needed to be done to strengthen such collaboration? If you are involved in course design and implementation of tertiary institutions, what would you be sure to include that will capture all aspects of graduate employability skills that leads to the production of a professional workready graduates. The four themes that emerged from the data representing the views of both the academic staff and employers was analyzed in the following section; The themes; through cooperative study programmes....'; often provide technical support and....' 'Through representation in the institutional management....; sometimes we share facilities such as.....' 
The theme, 'through cooperative study programme....' Was described by the respondents as the most popular and widely used collaborative means through which employers directly engaged higher institutions of learning particularly in planning and implementing courses/programmes design leading to the production of a work ready professional graduate. Both the academic staff and employers from industries have acknowledged the existence of such collaborative ventures notably among them was popularly known as 'SIWES' (Student Industrial Work Experience Scheme). This training programme forms a link between institutions and industries and the programme is part of the core course of the student's training. However, cooperation of industries in this pprogramme is required in the supervision of the students deployed to them. The intention of the scheme was basically to supplement the theoretical learning with practical occupational experience in industries in order to enhance the quality in terms of skill competency, effectiveness and efficiency of graduate in various occupational fields, which lead to developing the necessary skills, work attitudes and habits for job tenure and/or entry into other occupational instructional programmes. In a nutshell, it is viewed as a means to facilitate transition from school to world of work.

Having said that all these facts, a respondent has these to say;

"On the constraints that impinge on the success and effectiveness of the programmes for example, most educational institutions don't comply with the provision of the SIWES operational guidelines, such as making formal contact with the employers to assess the work environment, and facilities, so as to jointly work out or develop the industrial attachment experiences. The worst part of this situation is that many a times students are being sent to a place of their interest regardless of whether it is relevant to their field or not and they end up gaining little or no relevant experience at all."

Therefore, the dearth of meaningful relationship between institutions and world of work need to be properly addressed, if at all, such a programme is to bridge the skill gap mismatch between specialties studied in school and the employment market.

'Often, provide technical support and.....,' This theme characterized respondents views on the kind of collaboration through technical support and programme delivery, this can be in form of structured training programme or support, provided by industries for the students, such support may include anything from new work methods and procedures, management development, advanced courses intended to update knowledge and skills.

Majority of the respondents supported these and described it as laudable idea, particularly as majority of them express the notion, for example that, in consideration of the deteriorating situation of our tertiary institutions, the industries being the major stakeholders and potential consumer of the end products of these institutions though it wise and imperative to provide such technical assistance sometimes even through organizing seminars and workshops that can facilitate programme delivery.

One of the participants lamented as follows;

"I feel seeking institution working cooperation will surely yield a lot of positive results in developing work-ready graduates, for example my organization has a programme known as Graduate Attachment Programme (GAP). What we do here is that, graduate of tertiary institutions are recruited and attached to a willing company/industry for period of six months, it is expected that the attachee would have gained needed skills and practical experiences that would help address the skills mismatch. In addition, to these we also organize and arrange for seminars and workshops from time to time, where speakers from industries willing to give talks on industrial topics, the aim was to improve mutual understanding and exchange ideas between institutions and our company, through this we also provide the institutions (on request) career advice/other benefits which an institution can gain by the formation of an industrial link scheme, such as information concerning awareness of industrial work environment and processes and even at times we use to assist the institutions with a kind of projects in developing courses based on the industrial needs."

Nonetheless, majority of the respondents express the fear that, even though there are several other similar link programmes that exists, however, quiet a number of such collaborative programmes make little or no impact on graduate employability skill. Unless there is a practical skill framework in place upon which both the institutions and industries should work as a common front to address specific area of study. This can further provide direction and insight into what kind of assistance to provide an institution and what particular point in time.

The theme, 'through representation in the institutional...' is characterized by what the respondents' views on linking institutions with industries. This they express can be achieved through consultant pattern of the hierarchy of administrators and management of an institution. Majority of the participants uphold the views that a system through which a member representing an industry is been nominated in the Governing Council of an institution to represent the industrial sector still exists, but in an old tradition that does not seem to be insufficient for the purpose for which it was intended. The current practice of the institutions of having one person each from Manufacturers Association of Nigeria 
(MAN) and the Nigerian Society of Engineers (NSE) etc. representing Business and Industrial sectors at only the institutional governing council level is grossly inadequate. This is because the role they play which hitherto stands and limited to the management level of making administrative policy decisions only does not provide for those experts, the opportunity to impact or participate fully in providing the knowledge that decides on the programmes of study. How they should look like and even to share their own experiences with what is tenable in the institution except that they meet occasionally in some cases quarterly in a year.

'Sometimes we share facilities such as...' this theme characterized participant's opinion through what they expressed as 'shared facilities'. Majority of the participants indicated that, their institutions are faced with a persistent problem of lack of adequate provision and use of relevant educational facilities for training students which in many cases is not consistent with the job situation, this means that equipment, machinery and tools are either not adequate or up-todate, or their use does not represent that of an occupation for which the students are being prepared. The participants therefore believe that a strategy of 'shared facilities in training graduates represent a means of improving and contributing towards a quality education programme. The participants added further, that such collaboration of shared facilities forces the institutions to share the needs, problems, issues, strengths and weaknesses of a particular training programme of institutions occasionally, equipment, tools and instrument can be supplied sometimes in form of donations to the institutions and most importantly, sometimes visits to factory sites are organized for students, which also help the students to obtain a clear picture of industrial work life with opportunities and challenges.

\section{Discussions}

Findings from then study indicated that Business/Industry has a greater role to play in facilitating the transition from school to world of work, with a view to expose graduate for the industrial experience, especially in handling equipment and machinery which they are likely to meet after their graduation. The findings further revealed series of strategies and or linkages that exists, through which industries engaged the institutions in an attempt to facilitate the development of graduate employability skills, the most recognized and popular among them were, Cooperative Study Programme, Technical Support Programme and Programme delivery, industrial representation in the institutions management, and collaboration through shared facilities. Industry's, institution's collaborative efforts as indicated in the findings, being a popular method, cooperative study used to strengthen educational process of preparing graduate for employment in industry and related business organizations. The idea was to ensure that students acquire the much needed specificoccupational training skills, knowledge, judgment, understanding and attitudes in order to enhance the quality in terms of skill competency effectiveness and efficiency of graduates in various occupational fields. The findings further indicated that even though there are other arrangements in place, such as student visits to industrial site, on excursions from time to time to familiarize with the workplace, however, most prominent among them presently is current practice is known as SIWES, although the SIWES is considered as being part of the core course of the study programme, but the main problem as indicated by the participants was its inability to yield any meaningful, successful positive result since its inception reasons attributed to this not connected with the negligence attitudes on the part of the institutions and even the industries. In the findings it was further argued that constraints that impinge on its success and effectiveness include among other things, placement of students. In most cases institutions don't comply with the provision of the SIWES operational guidelines. For example, institutions don't place their students officially as quite often no formal contacts were made with industries, no assessment of industry's facilities is carried out, and invariably no jointly worked out programme of industrial attachment experiences were developed. Most seriously, however, desperate students get attached to wrong employers and end up gaining little or no relevant experiences that may be required in their field of study. Supervision of students has also been identified as one major problem, findings indicated that no effective supervision of the students by the institutions. In most cases, supervisors visit students for mere confirmation or verification since there were no training plans on what the students were expected to achieve at the end of the whole exercise.

Among the several other strategies, another means such as technical support and programme delivery, that ensure and facilitate training of graduate skills. This process aimed at supporting the institutions in programme delivery. Such programme as identified in this study include among other things graduate attachment programme (GAP) training for labour-based works, Community Development Scheme (CDS), capacity building workshops/seminars etc. all these are intended to improve mutual understanding and exchange of ideas between institutions and industries. In particular the findings also revealed that whole idea is to provide institutions sometimes even on request, speakers from industries willing to give talks on industrial topics, advice on career opportunities in industries, vocation employment for students who are interested in working in industry for short period. Assistance to various projects and the development of courses based on industrial needs, access to various reference sources not available in the institutions and special information 
concerning awareness, functions, structures of industrial work environment etc. It is to be noted however that, in as much as practices cane be adapted and used to achieve objectives, there is an overwhelming fear that such practices has not been consistent, organized and vibrant enough to produce positive results meaning to produce positive results. Meaning to say, the whole scenario has to change, to make things work for the better.

The study also found that, representations of industrial experts to serve in the institutions governing council even though still exists, however it was argued that, such an idea still exist in an old tradition and not adequately sufficient to serve its purpose because it does not provide such experts the opportunity to engage the academic department directly, with a view to fully participate in developing programme of study, how it should look like and even share and exchange experiences at various levels.

\section{Conclusions}

In conclusions, it has been acknowledged and recognized that institutions of higher learning accepted their responsibility of preparing professional graduates with employable skills capable of expanding labour market demand that can provide platform for sustainable economic growth and international competiveness of productive services. One of the most crucial issues facing both industries and Education is creating balance between the supply and demand in terms of graduate employability skills the problem which this study attempted to address. The study therefore through extensive review of literature, interviews captured the collective voices of experts, professionals, employers and academicians on how to develop graduate employability skills through Business/Industry collaboration ventures. Consequently, the study discovered series of strategies and or methods exists through which Business/Industry engaged the institutions in an attempt to develop and enhance graduate employability, the most recognized and popular among them were, cooperative study programme technical support and programme delivery, representation in the institution Governing Council and collaboration through shared facilities. With all these laudable strategies in place the study reveal that, such linkages have not been explored judiciously and effectively and therefore have not yielded any meaningful and positive results. Instead the institutions only continue to operate independently, developing programmes of study with little or no input from the Industry/Business sectors. And the consequences effect of this problem as discovered in this study shows that, institutions have their priority merely achieving 'academic excellence' which is adjudged only by the level of students who passed written examinations at the time of graduation. Contrary to the wishes of the industries who were singing or looking forward to have graduates with occupational competency regardless of their grade of passes in the final examination.

\section{References}

Butterwick, S., \& Benjamin, A. (2006). The road to employability through personal development: A critical analysis of the silences and ambiguities of the British Columbia (Canada) life skills. International Journal of Lifelong Education 25 (1), 75 - 86

Cresswell, J.W. (2009). Research Design: Qualitative, Quantitative and Mixed Method Approach (3rd ed) Sage publications

Employability Skills Framework stage 1 (2012), Final Report. Department of education employment and workplace relations.

Greenberg, J. A. (19984). Emerging pattern of cooperative arrangement: Journal of Studies in Technical Careers 250 -256

Hungerford, C. R. (1984). Towards a new scenario for University - Business collaboration in the Education and training of employee. Partnership for employee training: Implication for education and industry. Kansas State University: Higher Issues in Education

Jen, S. U. (2002). Issues and constraints in Polytechnic Education in Nigeria. Paraclete Publishing, Yola, Nigeria

Merriam, S. B. (2014). Qualitative Research: A guide to Design and Implementation. John Wesley and Sons

Moser, R. (1986). Business Industry linkages with post-secondary institutions: Implications for Building successful partnership. Lifelong learning $4-5$ and 27

Opengart, R. \& Short, D. (2002). Free agent learners: The new career model and its impact on human resource development. International journal of Lifelong Education, 22(1) 220 - 233.

Roth, G. L. (1987). Charting a new course for Industry and Education Partnerships. Journal of Vocational Education Research 27 -37

Sharman, S. W. (1983). Education for tomorrow's jobs Washington D. C. National academy press

Yin, R. K. (2003). Case Study Research: Design and Methods 3rd ed. Sage, Thousand Oaks, CA. 